\title{
Barotropic Forecasting with the Use of Surface Spherical Harmonic Representations
}

\author{
by
}

\author{
S. Kubota, M. Hirose, Y. Kikuchi and Y. Kurihara \\ Meteorological Research Institute, Tokyo \\ (Received January 26, 1961)
}

\begin{abstract}
The method to integrate the vorticity equation with the use of surface spherical harmonics has several advantages over the conventional method that uses the grid points. Namely, 1) no relaxation is required to solve the poisson equation, 2) we are not worried by the troubles accompanying the boundaries, 3) it has no such malignant truncation error as can be seen in the grid point method, which was already pointed out by Phillips, 4) square velocity and square vorticity are conserved. So, several points are explained here for preparations for the actual integration of barotropic equation.

First, selection rules of interaction coefficients to determine the combinations of disturbances which contribute to the variation of a certain disturbance and the method to calculate them are investigated. And the method how to expand the meteorological elements into the series of surface spherical harmonics, the individual points necessary for the actual integration are also presented, with one example.
\end{abstract}

\section{Introduction}

The spatial truncation errors, accompanying the conventional method of numerical integration of equations of motion or vorticity equation, have been considered to be unavoidable. Meanwhile, the method of expansion of meteorological quantities into the power series of some kind of functions has been considered to be advantageous in that they can avoid those kinds of errors, while how to determine the limit of the wave number of utilized waves has been left to be resolved. The latter question, we suppose, should be discussed in considering the observational results of spectrum distributions of atmospheric disturbances. Concerning this point, the surface spherical harmonic representations are supposed to be advantageous as compared with others, because the convergency of this representation has been found to be superior to others.

\section{Calculation of interaction coefficients}

We can expand the stream function on a certain isobaric surface into spherical harmonics as follows: 


$$
\phi=a^{2} \Omega \sum_{n_{1}=\left|m_{1}\right|+1}^{n_{1}^{\prime}} \sum_{m_{1}=-m_{1}{ }^{\prime}}^{m_{1}{ }^{\prime}} \phi_{n_{1}}^{m_{1}} Y_{n_{1}}^{m_{1}}
$$

where $a$ is the radius of the earth, $\Omega$ the angular velocity of the earth's rotation and $\psi_{n_{1}}^{m_{1}}$ the harmonic coefficient in complex, $Y_{n}^{m}$ is a surface spherical harmonic and is defined by the associated Legendre function of the first kind of order $m$ and degree $n$,

$$
Y_{n}^{m}=e^{i m \lambda} P_{n}^{m}
$$

Here, $P_{n}^{n}$ is normalized to unity,

$$
\begin{aligned}
\int_{-\frac{\pi}{2}}^{\frac{\pi}{2}} P_{n}^{m} P_{s}^{m} \cos \varphi d \varphi=\delta_{n s}, \\
\delta_{n s}=1 \quad \text { if } \quad n=s \\
=0 \text { if } n \neq s,
\end{aligned}
$$

and satisfies the following relation:

$$
P_{n}^{-m}=(-1)^{m} P_{n}^{m}
$$

In our case, $m_{1}{ }^{\prime}$ in (1) is twelve. And $n_{1}-m_{1}$ is an odd integer, as the stream function is assumed to be an odd function with respect to the equator. The maximum of $\left(n_{1}-m_{1}\right)$, is 15 .

Then, we can obtain the time change of $\phi_{n_{1}}^{m_{1}}$ by the following equation, which is derived by substituting (1) into the vorticity equation for the barotropic model:

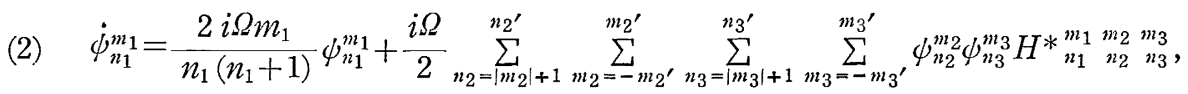

where $n_{2}-\left|m_{2}\right|$ and $n_{3}-\left|m_{3}\right|$ are odd integers and $m_{2}^{\prime}=m_{3}^{\prime}=12, n_{2}^{\prime}=\left|m_{2}\right|+15$ and $n_{3}^{\prime}=\left|m_{3}\right|+15$ in our case. $H^{* m_{1}} n_{n_{2}}^{m_{2}} n_{3} m_{3}$ is a coefficient which represents to what extent the coupling between $\phi_{n_{2}}^{m_{2}}$ and $\phi_{n_{3}}^{m_{3}}\left(m_{3}=m_{1}-m_{2}\right)$ contritutes to the change of $\phi_{n_{1}}^{m_{1}}$. $H^{* m_{1}} m_{n_{1}}^{m_{2}} n_{2} m_{3} n_{3}$ is written as

$$
H_{n_{1} n_{2} n_{3}}^{* m_{1} m_{2} m_{3}}=\frac{n_{2}\left(n_{2}+1\right)-n_{3}\left(n_{3}+1\right)}{n_{1}\left(n_{1}+1\right)} \int_{-\frac{\pi}{2}}^{\frac{\pi}{2}} P_{n_{1}}^{m_{1}}\left\{m_{2} P_{n_{2}}^{m_{2}} \frac{\partial P_{n_{3}}^{m_{3}}}{\partial \varphi}-m_{3} P_{n_{3}}^{m_{3}} \frac{\partial P_{n_{2}}^{m_{2}}}{\partial \varphi}\right\} d \varphi,
$$

and has the relations

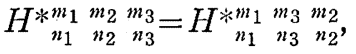

$$
\begin{aligned}
& H * m_{1}^{* m_{1}} m_{2} m_{2} m_{3}=0 \text {, if } n_{2}=n_{3} \text {, or } m_{1} \neq m_{2}+m_{3} \text {. }
\end{aligned}
$$

Consequently, the summation in (2) can be simplified as follows:

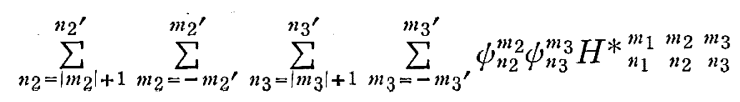




$$
=\sum_{\substack{n_{2}=\left|m_{2}\right|+1, \\ \text { and } n_{2}>n_{3}}}^{n_{2} m_{2}=-m_{2^{\prime}} n_{3}=\left|m_{3}\right|+1} \sum_{m_{3}=-m_{3^{\prime}}}^{m_{2^{\prime}} n_{3^{\prime}}} \phi_{n_{2}}^{m_{2}} \phi_{n_{3}}^{m_{3}} H_{n_{1}}^{m_{1}} n_{2} n_{2} n_{3},
$$

where

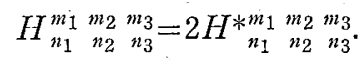

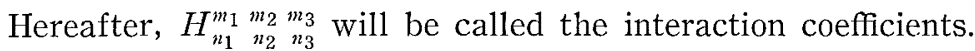

In our study, calculation of $H$ was performed by the method given by SILBERMAN. Let

$$
L_{n_{1} n_{2} n_{3}}^{m_{1} m_{2} m_{3}}=\int_{-\frac{\pi}{2}}^{\frac{\pi}{2}} P_{n_{1}}^{m_{1}}\left(m_{2} P_{n_{2}}^{m_{2}} \frac{\partial P_{n_{3}}^{m_{3}}}{\partial \varphi}-m_{3} \frac{\partial P_{n_{2}}^{m_{2}}}{\partial \varphi} P_{n_{3}}^{m_{3}}\right) d \varphi
$$

then,

$$
H_{n_{1} n_{2} n_{3}}^{m_{1} m_{2} m_{3}}=2 \frac{n_{2}\left(n_{2}+1\right)-n_{3}\left(n_{3}+1\right)}{n_{1}\left(n_{1}+1\right)} L_{n_{1} n_{2} n_{3}}^{m_{1} m_{2}} m_{3} .
$$

In the following, the evaluation of $L$ will be made with the assumption that $m_{1}, m_{2}$ and $m_{3}$ are not negative. This does not lose generality at all, as

$$
\begin{aligned}
& L_{n_{1} n_{2} n_{2} n_{3}}^{m_{2} m_{3}}=(-1)^{m_{2}} L_{n_{3} n_{2} n_{2} n_{1}\left|m_{2}\right| m_{1}}, \\
& \text { if } m_{2}<0
\end{aligned}
$$

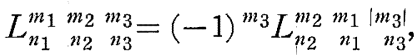

$$
\begin{aligned}
& \text { if } m_{3}<0 \text {. }
\end{aligned}
$$

$L$ can be expressed by the following formula :

$$
L_{n_{1} n_{2}}^{m_{1} m_{3}} m_{3}=-E_{n_{1}}^{m_{1} n_{2}} m_{2} m_{3}+E_{n_{1} n_{3}}^{m_{1}} m_{2} m_{2},
$$

where

$$
\begin{aligned}
E_{n_{1} n_{2} n_{3}}^{m_{1} m_{2} m_{3}} & =m_{3}\left[\left(n_{2}+m_{2}+1\right)\left(n_{2}-m_{2}\right)\right]^{\frac{1}{2}} \int_{-\frac{\pi}{2}}^{\frac{\pi}{2}} P_{n_{1}}^{m_{1}} P_{n_{2}}^{m_{2}+1} P_{n_{3}}^{m_{3}} d \varphi \\
= & m_{3}\left[\frac{\left(2 n_{2}+1\right)\left(n_{2}-m_{2}\right) !}{\left(n_{2}+m_{2}\right) !}\right]^{\frac{1}{2}} \\
& \times \sum_{q}\left[\frac{(2 q+1)\left(q+m_{2}\right) !}{\left(q-m_{2}\right) !}\right]^{\frac{1}{2}} \int_{-\frac{\pi}{2}}^{\frac{\pi}{2}} P_{n_{1}}^{m_{1}} P_{q}^{m_{2}} P_{n_{3}}^{m_{3}} \cos \varphi d \varphi .
\end{aligned}
$$

In (8), the values of $q$ to be used for summation are

$$
q=n_{2}-1, n_{2}-3, \cdots \cdots, m_{2}+1 \text { or } m_{2} \text {. }
$$

As has been shown by INFELd and Hull (1951), the integral in (8), for the case $m_{1}=m_{2}+m_{3}$, becomes

$$
\text { (9) } \begin{aligned}
& \int_{-\frac{\pi}{2}}^{\frac{\pi}{2}} P_{n_{1}}^{m_{1}} P_{q}^{m_{2}} P_{n_{3}}^{m_{3}} \cos \varphi d \varphi \\
& =\frac{\left(n_{3}+q-n_{1}-1\right) ! !\left[\left(2 n_{1}+1\right)(2 q+1)\left(2 n_{3}+1\right)\right]^{\frac{1}{2}}}{\left(n_{3}+n_{1}-q\right) ! !\left(q+n_{1}-n_{3}\right) ! !\left(n_{1}+q+n_{3}+1\right) ! !}
\end{aligned}
$$




$$
\begin{aligned}
& \times\left[\frac{\left(n_{1}+m_{1}\right) !\left(n_{1}-m_{1}\right) !\left(q-m_{2}\right) !\left(n_{3}-m_{3}\right) !}{2\left(q+m_{2}\right) !\left(n_{3}+m_{3}\right) !}\right]^{\frac{1}{2}} \\
& \times \sum_{h=0}^{n_{1}-m_{1}} \frac{(-1)^{\left(n_{3}-q+n_{1}\right) / 2+m_{3}+h}\left(n_{3}+m_{3}+h\right) !\left(q+n_{1}-m_{3}-h\right) !}{\left(n_{1}-m_{1}-h\right) ! h !\left(n_{3}-m_{3}-h\right) !\left(q-n_{1}+m_{3}+h\right) !},
\end{aligned}
$$

where $n ! !=n(n-2)(n-4) \cdots \cdots 2$ or $1,0 ! !=(-1) ! !=1$. This integral vanishes

unless

$$
\left\{\begin{array}{l}
n_{1}+q+n_{3}=\text { even integer } \\
\left|n_{3}-q\right| \leq n_{1} \leq n_{3}+q .
\end{array}\right.
$$

By making use of the the above-mentioned formulae and conditions, (5) through (10), the interaction coefficients $H_{n_{1}}^{m_{1} n_{2} n_{2} n_{3}}$ can be calculated.

We used IBM 704 electronic computor for the calculation of $H$. The ordering of indices and the selection rules which we adopted at the machine computation

\begin{tabular}{|c|c|c|}
\hline A & B & $\mathrm{C}$ \\
\hline $\begin{array}{llll}m_{1}=0 & \text { (1) } & 12 \\
n_{1}=m_{1}+1 & \text { (2) } & m_{1}+15 \\
m_{2}=m_{1}-12 & \text { (1) } 12 \\
m_{3}=m_{1}-m_{2} & \\
n_{3}=\left|m_{3}\right|+1 & \text { (2) } & \left|m_{3}\right|+15 \\
n_{2}=\left|m_{2}\right|+1 & \text { (2) } & \left|m_{2}\right|+15\end{array}$ & $n_{2}>n_{3}$ & $\left|n_{1}-n_{3}\right|<n_{2}<n_{1}+n_{3}$ \\
\hline
\end{tabular}
are listed in Table 1.

Table 1. Ordering of indices and selection rules.

Column $A$ shows the ordering and the conditions on indices. Here, $m=A(B) C$ means that $m$ takes the values in sequence from $A$ to $C$ with the interval of $B$, i.e. $m=A, A+B, A+2 B, \cdots \cdots, C$. The ordering rule is that the first index, e.g. $m_{1}$ in our case, will be varied after all other indices are varied, and so on. As mentioned above, $n_{i}-\left|m_{i}\right|$ must be an odd integer as the stream function is an odd function with respect to the equator in our case. Of course, $m_{2}+m_{3}$ must be equal to $m_{1}$. The numerical limits for $m_{i}$, i.e. $0 \leqq\left|m_{i}\right| \leqq 12$, and $n_{i}$, i.e. $1 \leqq n_{i}-\left|m_{i}\right| \leqq 15$ are imposed by us. Columns $B$ and $C$ show the selection rule. If the indices do not satisfy these conditions, the calculation of $H$ for such indices is unnecessary. Then the next indices in the ordering rule are taken up and it is examined whether they satisfy the selection rule. The condition in Column $B$ results directly from the condition of summation on the right hand-side of the formula (4). The condition $C$ are derived from the condition (10) and the formulae (7), (8) and (9). From (10), it follows also that $H_{n_{1} n_{2} m_{3} m_{3}}^{m_{2}}$ is zero unless $n_{1}+n_{2}+n_{3}=$ an odd integer. But this condition is not included in the selection rule, as $\left(n_{1}+n_{2}+n_{3}\right)$ is always an odd integer when the indices satisfy the condition in Column $A$.

At the beginning of the machine computation, $\log n$ for $n=1$ (1) $100, \log (n-1)$ ! for $n=1$ (1) 90 and $\log (n-2)$ !! for $n=1$ (1) 120 were computed and stored as the fundamental table. Computations for the formulae (8) and (9) were mostly performed by using this table. At the summation in the right-hand side of $(9),(k+1)$-th term was obtained by multiplying $k$-th term, for which $h=k-1$, by 


$$
(-1.0) \times \frac{\left(n_{3}+m_{3}+k\right)\left(n_{1}-m_{1}-k+1\right)\left(n_{3}-m_{3}-k+1\right)}{\left(q+n_{1}-m_{3}-k+1\right) \cdot k \cdot\left(q-n_{1}+m_{3}+k\right)},
$$

if $k$-th term was not zero.

As $m_{3}=m_{1}+m_{2}$, five indices are dependent variables. So, for each fixed value of $m_{1}$ and $n_{1}$, the computed values of $H_{n_{1} n_{2} m_{2} m_{3}}^{m_{3}}$ were temporarily stored in the threedimensional data field, i.e. $H$, in the machine. The location in which $H_{n_{1}}^{n_{1} n_{2} n_{2} n_{3}}$ was stored was $H(N 2 T, N 3 T, M 2 T)$,

where

$$
\begin{aligned}
& N 2 T=\frac{n_{2}-\left|m_{2}\right|+1}{2}, \\
& N 3 T=\frac{n_{3}-\left|m_{3}\right|+1}{2},
\end{aligned}
$$

and

$$
M 2 T=m_{2}+13 .
$$

$N 2 T, N 3 T$ and $M 2 T$ are integers, and have the value between 1 and 8 , between 1 and 8 and between 1 and 25, respectively. Therefore, the total number of $H$-field was 1600 . When the indices did not satisfy the selection rule which was mentioned above, the content of the storage for the concerned indices remained clear. And before changing $n_{1}$ or $m_{1}$, all 1600 values were written on a magnetic tape as one record. As the range of $m_{1}$ was 13 , i.e. 0 (1) 12 , and that of $n_{1}$ was 8 , i.e. $m_{1}+1$ (2) $m_{1}+15,104$ records in a tape constituted one file of the interaction coefficients.

\begin{tabular}{|c|c|c|c|c|c|c|c|c|c|c|c|c|c|}
\hline$n_{1}-m_{1} m_{1}$ & 0 & 1 & 2 & 3 & 4 & 5 & 6 & 7 & 8 & 9 & 10 & 11 & 12 \\
\hline 1 & 0 & 180 & 161 & 288 & 255 & 340 & 298 & 352 & 306 & 344 & 305 & 336 & 301 \\
\hline 3 & 175 & 335 & 298 & 407 & 358 & 427 & 371 & 411 & 358 & 388 & 342 & 365 & 323 \\
\hline 5 & 324 & 464 & 410 & 501 & 437 & 490 & 421 & 453 & 394 & 416 & 364 & 379 & 332 \\
\hline 7 & 446 & 566 & 496 & 569 & 491 & 528 & 454 & 478 & 414 & 428 & 371 & 379 & 329 \\
\hline 9 & 540 & 640 & 555 & 610 & 519 & 548 & 470 & 486 & 418 & 424 & 364 & 366 & 315 \\
\hline 11 & 605 & 685 & 586 & 623 & 529 & 550 & 469 & 477 & 406 & 405 & 344 & 341 & 291 \\
\hline 13 & 640 & 700 & 588 & 617 & 521 & 534 & 451 & 451 & 379 & 372 & 312 & 305 & 258 \\
\hline 15 & 644 & 684 & 571 & 592 & 495 & 500 & 416 & 409 & 338 & 326 & 269 & 259 & 217 \\
\hline total & 74 & 254 & & 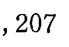 & 605 & 17 & 350 & 517 & 13 & 03 & 671 & 730 &, 366 \\
\hline
\end{tabular}
Table 2 shows the number of coefficients which were computed as indices satisfied the selection rule. Total number is 43772 .

Table 2. Number of interaction coefficient.

grand total $=43,772$.

The interaction coefficients have been computed by Baer. Some comparisons between his result and ours are represented in Table 3 . As a slight difference exists in the normalization factor of $P_{n}^{n}$ and so on, our result is multiplied by $1 / \sqrt{2}$ for the sake of comparison.

In order to calculate the interaction coefficient, we used the formulae (5) through 
Table 3. Some comparisons between Baer's coefficient and ours.

\begin{tabular}{rrrrrr|r|r}
\hline \hline$m_{1}$ & $n_{1}$ & $m_{2}$ & $n_{2}$ & $m_{3}$ & $n_{3}$ & $H_{n_{1} n_{2} m_{3} m_{3}}^{m_{2} m_{3}} / \sqrt{2}$ & Baer's result \\
\hline 3 & 4 & 2 & 3 & 1 & 2 & 0.67082 & 0.67082 \\
3 & 4 & 3 & 4 & 0 & 3 & 1.73176 & 1.73176 \\
7 & 8 & 5 & 8 & 2 & 3 & -13.53664 & -13.53663 \\
7 & 12 & 5 & 10 & 2 & 3 & -6.58583 & -6.58584 \\
14 & 17 & 2 & 19 & 12 & 17 & -23.31074 & -23.31081 \\
16 & 17 & 0 & 19 & 16 & 17 & -2.74619 & -2.74603 \\
16 & 17 & 16 & 19 & 0 & 3 & 23.60126 & 23.60140 \\
\hline
\end{tabular}

(9). But, it may be obtained also by the numerical integration of the right-hand side of (5). We carried out the test computation for the case of $m_{1}=0, n_{1}=5$, $m_{2}=-1, n_{2}=4, m_{3}=1$ and $n_{3}=2$, by using unnormalized value of $P_{n}^{m}$. The results of numerical integration by Sympson's law with the use of the values at every one degree latitude, two degrees and three degrees were $L_{5}^{0-1} \frac{1}{2}=7.2451,7.0099$ and 7.0955 , respectively. While the accurate value is 7.2727 .

\section{Evaluation of the surface spherical harmonic coefficients}

In order to perform the numerical prediction with the use of surface spherical harmonic representation of basic equations, the evaluation of expansion coefficients of the quantities given initially ( $500 \mathrm{mb}$ height in our case) is required.

The height of $500 \mathrm{mb}$ surface $z$ can be expanded with the surface spherical harmonic series as follows:

$$
z=\frac{1}{2} \sum_{n=0}^{N} A_{n}^{0} P_{n}^{0}(\sin \varphi)+\sum_{m=1}^{M} \sum_{n=m}^{m+N}\left(A_{n}^{m} \cos m \lambda+B_{n}^{m} \sin m \lambda\right) P_{n}^{m}(\sin \varphi),
$$

where

$$
\begin{aligned}
& A_{n}^{m}=\frac{1}{2 \pi} \int_{0}^{2 \pi} \int_{-\frac{\pi}{2}}^{\frac{\pi}{2}} z \cos m \lambda P_{n}^{m}(\sin \varphi) \cos \varphi d \varphi d \lambda, \quad(m \geqq 0) \\
& B_{n}^{m}=\frac{1}{2 \pi} \int_{0}^{2 \pi} \int_{-\frac{\pi}{2}}^{\frac{\pi}{2}} z \sin m \lambda P_{n}^{m}(\sin \varphi) \cos \varphi d \varphi d \lambda, \quad(m \geqq 1)
\end{aligned}
$$

$\lambda$ is longitude, $\varphi$ is latitude and $P_{n}^{m}(\sin \varphi)$ is the normalized associated Legender function. If it can be assumed that $500 \mathrm{mb}$ height is symmetric with respect to the equator, the harmonic coefficients may be evaluated only from the observed data covering the whole northern hemisphere. In general, however, it is difficult to obtain the data over the whole northern hemisphere, e.g., the lack of the data can be seen usually in the region near the equater. For this, two methods will be considered in order to evaluate the harmonic coefficients. One is the least square method and the other is to estimate the integrals in (12) and (13) after extrapolating the values of height to cover the region having few observations.

In the first place, we tried the evaluation of the harmonic coefficients by the least square method. 
If $C_{m}(\varphi)$ and $S_{m}(\varphi)$ satisfy the following relations:

$$
C_{m}(\varphi)=\sum_{n=m}^{m+N} A_{n}^{m} P_{n}^{m}(\sin \varphi) \quad(m \geqq 0)
$$

and

$$
S_{m}(\varphi)=\sum_{n=m}^{m+N} B_{n}^{m} P_{n}^{m}(\sin \varphi),
$$

equation (1) can be written in the form

$$
z=\frac{1}{2} C_{0}(\varphi)+\sum_{m=1}^{M}\left[C_{m}(\varphi) \cos m \lambda+S_{m}(\varphi) \sin m \lambda\right] .
$$

The values of $C_{m}(\varphi)$ 's and $S_{m}(\varphi)$ 's may be obtained by the usual methods of evaluation of Fourier coefficients at every latitude with observed data. Thus the problem is how to determine the coefficients $A_{n}^{m}$ 's to minimize the value of $F$, which is expressed by

$$
F=\sum_{i=1}^{I}\left[\sum_{n=m}^{m+N} A_{n}^{m} P_{n}^{m}\left(\sin \varphi_{i}\right)-C_{m}\left(\varphi_{i}\right)\right]^{2}
$$

$\varphi_{i}$ 's denoting the latitudes where the values of height will be read. It is same with coefficients $B_{n}{ }^{m}$ 's. This procedure will be equivalent to solving the following matrix equations for $\boldsymbol{A}_{m}$ and $\boldsymbol{B}_{m}$ at each $m$ from $m=0$ to $m=M$ :

$$
\boldsymbol{E}_{m} \boldsymbol{A}_{m}=\boldsymbol{C}_{m},
$$

and

$$
\boldsymbol{E}_{m} \boldsymbol{B}_{m}=\boldsymbol{S}_{m}
$$

where

$$
\begin{aligned}
& \boldsymbol{A}_{m}=\left[\begin{array}{l}
A_{m}^{m} \\
A_{m+1}^{m} \\
\vdots \\
\vdots \\
A_{m+N}^{m}
\end{array}\right], \quad \boldsymbol{B}_{m}=\left[\begin{array}{l}
B_{n}^{m} \\
B_{m+2}^{n} \\
\vdots \\
\vdots \\
B_{m+N}^{m}
\end{array}\right], \quad \boldsymbol{C}_{m}=\left[\begin{array}{c}
C_{m}^{m} \\
C_{m+1}^{n} \\
\vdots \\
\vdots \\
C_{m+N}^{m}
\end{array}\right], \quad \boldsymbol{S}_{m}=\left[\begin{array}{l}
S_{m}^{m} \\
S_{m+1}^{m} \\
\cdots \\
\vdots \\
S_{m+N}^{m}
\end{array}\right],
\end{aligned}
$$

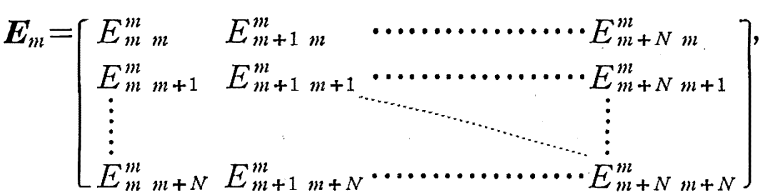

with

$$
\begin{aligned}
& C_{l}^{m}=\sum_{i=1}^{I} C_{m}\left(\varphi_{i}\right) P_{l}^{m}\left(\sin \varphi_{i}\right), \\
& S_{l}^{m}=\sum_{i=1}^{I} S_{m}\left(\varphi_{i}\right) P_{l}^{m}\left(\sin \varphi_{i}\right),
\end{aligned}
$$

and

$$
E_{n l}^{m}=\sum_{i=1}^{I} P_{n}^{m}\left(\sin \varphi_{i}\right) P_{l}^{u}\left(\sin \varphi_{i}\right)
$$


If $\boldsymbol{E}_{m}^{-1}$ is the inverse matrix of $\boldsymbol{E}_{m}$, the solutions of (16) and (17) will be given by

and

$$
\boldsymbol{A}_{m}=\boldsymbol{E}_{m}^{-1} \boldsymbol{C}_{m}
$$

$$
\boldsymbol{B}_{m}=\boldsymbol{E}_{m}^{-1} \boldsymbol{S}_{m}
$$

When the latitudes where the values of height can be read are fixed, these $\boldsymbol{E}_{m}^{-1}$ 's will express constant matrices, the elements of which are to be evaluated from the associated Legendre function. Therefore, these matrices can be calculated once for all.

The coefficients $A_{n}^{m}$ 's and $B_{n}^{m}$ 's of $500 \mathrm{mb}$ height of 14 th September 1958 were computed by the above method for $M=18$ and $N=16$ from the values, north of $15^{\circ} \mathrm{N}$, read at every 5 degrees of longitude and latitude. The results are shown in Table 4. The coefficients with $n-m$ of an odd integer vanish because of the assumption of symmetry of $500 \mathrm{mb}$ height with respect to the equator. It is seen from the table that the values of coefficients are on the whole large, and increase with the increase of the wave number $m$, in spite of the expectation of an opposite tendency.

Table 4. The surface spherical harmonic coefficients $\left(A_{n}^{m}\right)$ computed by the least square method.

\begin{tabular}{c|rrrrrrrrr}
\hline \multicolumn{1}{c}{$n-m$} & \multicolumn{1}{c}{0} & \multicolumn{1}{c}{2} & \multicolumn{1}{c}{4} & \multicolumn{1}{c}{6} & 8 & 10 & 12 & 14 & 16 \\
\hline 0 & $8,127.4$ & -233.0 & -83.6 & 29.2 & -7.0 & -11.6 & -3.6 & 9.5 & -0.1 \\
1 & 79.8 & -42.1 & 33.8 & -71.3 & 31.2 & -22.2 & 29.1 & -18.8 & 13.5 \\
2 & 41.4 & 12.1 & 39.3 & 9.6 & 5.8 & -11.0 & 7.7 & -2.3 & 0.6 \\
3 & 23.7 & 15.6 & 55.7 & 8.7 & -0.3 & -8.2 & 9.2 & 2.6 & 3.0 \\
4 & -70.2 & 59.0 & -25.2 & 57.1 & -18.4 & 31.2 & -6.2 & 9.0 & -10.2 \\
5 & -20.5 & 20.2 & 1.6 & 20.6 & -0.2 & 12.3 & -5.4 & 0.2 & -4.1 \\
6 & -14.4 & 3.7 & -27.6 & -15.3 & -8.6 & 12.0 & 5.1 & 5.5 & 2.5 \\
7 & 139.4 & -100.6 & 57.9 & -65.2 & 40.8 & -22.9 & 23.4 & -9.4 & 4.8 \\
8 & 198.8 & -111.7 & 114.7 & -62.6 & 47.8 & -40.5 & 17.8 & -16.8 & 7.0 \\
9 & 164.0 & -100.2 & 86.5 & -47.2 & 42.9 & -23.8 & 13.6 & -10.9 & 1.6 \\
10 & -272.7 & 176.3 & -119.9 & 89.0 & -57.8 & 37.8 & -24.3 & 11.5 & -6.3 \\
11 & -758.9 & 461.8 & -318.6 & 230.8 & -155.7 & 91.8 & -51.6 & 25.2 & -8.8 \\
12 & 383.5 & -228.0 & 157.1 & -112.7 & 65.1 & -45.7 & 21.4 & -10.3 & 3.7 \\
13 & -300.9 & 179.1 & -118.7 & 80.2 & -53.2 & 30.4 & -17.2 & 6.4 & -3.6 \\
14 & -138.3 & 77.1 & -47.2 & 30.9 & -14.5 & 9.3 & 0.3 & -0.9 & 1.0 \\
15 & 261.3 & -141.4 & 90.8 & -57.1 & 34.3 & -14.4 & 6.1 & -0.6 & -0.3 \\
16 & -114.4 & 54.5 & -31.0 & 12.3 & -3.2 & -3.4 & 6.2 & -4.7 & 5.5 \\
17 & $-1,315.0$ & 710.4 & -447.1 & 273.7 & -160.4 & 81.2 & -36.9 & 12.5 & -2.8 \\
18 & $4,085.3$ & $-2,186.1$ & $1,355.0$ & -825.8 & 470.9 & -244.7 & 108.4 & -39.5 & 8.6 \\
\hline & & & & & & & &
\end{tabular}

Then, we considered about the second method, that is, extrapolation and integration. The extrapolation of $500 \mathrm{mb}$ height into the region from $15^{\circ} \mathrm{N}$ to the equator was made so that on the equator the mean zonal height might take its normal value. In the estimation of the integrals in (12) and (13), Simpson's one third rule was 
employed for the same data as used in Table 4 under the same assumption of symmetry. The results, giving reasonable values, are shown in Table 5 .

Table 5. The surface spherical harmonic coefficients $\left(A_{n}^{m n}\right)$ computed by the method of extrapolation and integration.

\begin{tabular}{|c|c|c|c|c|c|c|c|c|c|}
\hline$m \quad n-m$ & 0 & 2 & 4 & 6 & 8 & 10 & 12 & 14 & 16 \\
\hline 0 & $5,856.5$ & -241.8 & -76.4 & 22.4 & -1.1 & -16.6 & -0.2 & 6.8 & 2.2 \\
\hline 1 & 15.7 & 14.8 & -18.4 & -26.2 & -8.3 & 8.4 & 6.2 & -2.8 & 2.6 \\
\hline 2 & 22.5 & 27.7 & 25.8 & 21.2 & -4.5 & -4.1 & 2.5 & 1.1 & -0.8 \\
\hline 3 & 5.9 & 28.9 & 44.1 & 18.5 & -7.9 & -2.7 & 5.0 & 4.1 & 1.4 \\
\hline 4 & 2.4 & 5.8 & 18.7 & 20.8 & 9.7 & 10.6 & 8.8 & -1.0 & -7.0 \\
\hline 5 & 0.1 & 5.7 & 13.8 & 11.3 & 7.6 & 5.8 & -0.7 & -2.4 & -1.1 \\
\hline 6 & 0.5 & -6.1 & -20.3 & -21.9 & -4.6 & 9.0 & 7.3 & 4.7 & 4.0 \\
\hline 7 & -1.4 & -7.0 & -13.8 & -10.5 & 0.1 & 5.4 & 4.4 & 0.5 & 0.8 \\
\hline 8 & 4.5 & 14.8 & 19.1 & 8.8 & -4.1 & -4.7 & -4.2 & -3.7 & 0.9 \\
\hline 9 & -0.6 & 4.0 & 10.3 & 8.7 & 4.5 & 1.9 & -0.9 & -3.0 & -1.9 \\
\hline 10 & 1.9 & 5.5 & 3.0 & 1.0 & 2.3 & -0.9 & -1.7 & 0.1 & -1.4 \\
\hline 11 & 0.1 & 1.3 & 5.8 & 4.1 & -3.7 & -1.8 & 2.0 & -1.0 & -0.5 \\
\hline 12 & -0.7 & 0.3 & -0.4 & -4.7 & -5.2 & -3.1 & -1.1 & 0.2 & -0.4 \\
\hline 13 & 0.8 & 2.1 & 1.5 & -0.3 & -1.4 & -1.0 & -0.4 & -1.1 & -1.5 \\
\hline 14 & 0.1 & 0.7 & 1.2 & 1.7 & 2.0 & 2.0 & 1.4 & -0.2 & -0.1 \\
\hline 15 & 1.7 & 2.4 & -0.2 & -0.6 & 1.7 & 1.8 & -0.5 & 0.1 & 0.8 \\
\hline 16 & -0.2 & -1.2 & -1.4 & -0.8 & -1.0 & -0.3 & 1.2 & 1.5 & 2.0 \\
\hline 17 & -1.8 & -2.4 & -0.4 & -0.5 & -1.8 & -2.4 & -0.4 & 0.7 & -0.7 \\
\hline 18 & 0.7 & 1.8 & 0.8 & -1.3 & -0.9 & 0.5 & -1.0 & -1.1 & 0.8 \\
\hline
\end{tabular}

There is little difference between the heights reproduced from the coefficients obtained by those two methods. Therefore, the coefficients evaluated by the least square method are supposed to be suitable for the reproduction of the original field, but their values themselves do not seem to be physically significant. Of course, if the data covering the region from equator to pole are used, the significant coefficients may also be obtained by the least square method.

It is certainly a difficult point to decide how many terms should be taken into account in the series for practical use. However, we tried to see to what extent the height field can be reproduced accurately by composing the wave components assuming the various values of $M$ and $N$ which denote the maximum wave numbers along a latitude circle and between poles respectively. Table 6 shows the root mean square of the difference between the reproduced field and the original one. With the increase of $M$ and $N$, the root mean square decreases rapidly within small $M$ and $N$, but become slow with large $M$ and $N$ beyond 12 and 14 respec-

Table 6. The root mean square of difference between original and reproduced fields for the various maximum values of $m$ and $n$.

\begin{tabular}{r|rrrr}
\hline \hline$N-M$ & 10 & 12 & 14 & 16 \\
\hline 12 & & 20.6 & & \\
14 & 19.5 & 17.5 & 16.9 & 16.4 \\
16 & & 16.3 & & \\
18 & & 15.4 & & \\
\hline
\end{tabular}


tively. Thus we have determined to adopt the values of $M=12$ and $N=14$ in the following calculations.

\section{Geostrophic relation and time interval}

To integrate the barotropic equation, we must determine the stream function from the geopotential of $500-\mathrm{mb}$ surface. For this, we have adopted the relations,

$$
\begin{aligned}
f \nabla^{2} \psi & =\nabla^{2} \phi, \\
\phi & =a^{2} \Omega \sum_{n=|m|+1}^{n^{\prime}} \sum_{m=-m^{\prime}}^{n^{\prime}} \Psi_{n}^{m} Y_{n}^{m}, \\
\phi & =g Z=a^{2} \Omega^{2} \sum_{n=|m|}^{n^{\prime}} \sum_{m=-m}^{m^{\prime}} \Phi_{n}^{m} Y_{n}^{m},
\end{aligned}
$$

which will be found to be equivalent to the equation,

$$
\Psi_{n+1}^{m}=\frac{n}{n+2}\left[\frac{4(n+1)^{2}-1}{(n+1)^{2}-m^{2}}\right]^{\frac{1}{2}}\left\{\frac{1}{2} \Phi_{n}^{m}-\frac{n-1}{n+1}\left[\frac{n^{2}-m^{2}}{4 n^{2}-1}\right]^{\frac{1}{2}} \Psi_{n-1}^{m}\right\}
$$

and the following time scheme is used for the integration:

$$
\begin{aligned}
\alpha_{1} & =\alpha_{0}+\frac{1}{4} \delta t \cdot\left(\frac{\partial \alpha}{\partial t}\right)_{0}, \\
\alpha_{2} & =\alpha_{0}+\frac{1}{2} \delta t \cdot\left(\frac{\partial \alpha}{\partial t}\right)_{1}, \\
\alpha_{3} & =\alpha_{0}+\delta t \cdot\left(\frac{\partial \alpha}{\partial t}\right)_{2} \\
\alpha_{4} & =\alpha_{0}+2 \delta t \cdot\left(\frac{\partial \alpha}{\partial t}\right)_{3}, \quad \text { for } \tau \geqslant 4 \\
\alpha_{\tau+1} & =\alpha_{\tau-1}+2 \delta t \cdot\left(\frac{\partial \alpha}{\partial t}\right)_{\tau}:
\end{aligned}
$$

In this case, the number of forward extrapolations at the beginning of the integration may be supposed to be too large, but we dared to adopt the above scheme for $\delta t \equiv 3$ hours.

In this calculation, most of the machine time was found to have been spent for reading and rewinding the interaction functions in the tape. And at the beginning of our work, 70 minutes or more were presumed to be required for one day integration, but it was found later that it can be shortened to about seventeen minutes. The main reasons for this shortening are that 1) the indices to be used for the selection of coefficients are calculated in advance, 2) two tapes storing the interaction functions are used and the simultaneous performance of reading and rewinding has become possible, 3) and at last the necessary of tapes itself became very short by canning four words (one interaction function, three indices necessary for selection of disturbances) into one memory.

\section{One example}

To investigate the above scheme of calculation, we will present here one result. 


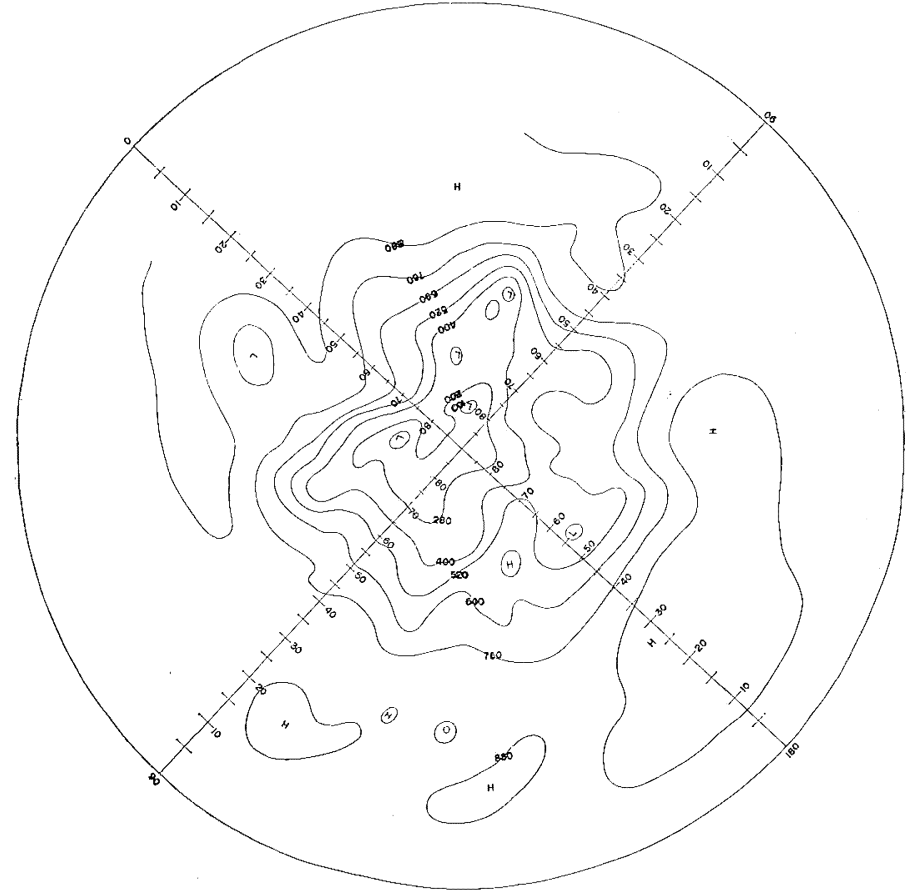

Fig. 1. Chart $(Z)$ for 1958 , Sept. 14, $500 \mathrm{mb}$.

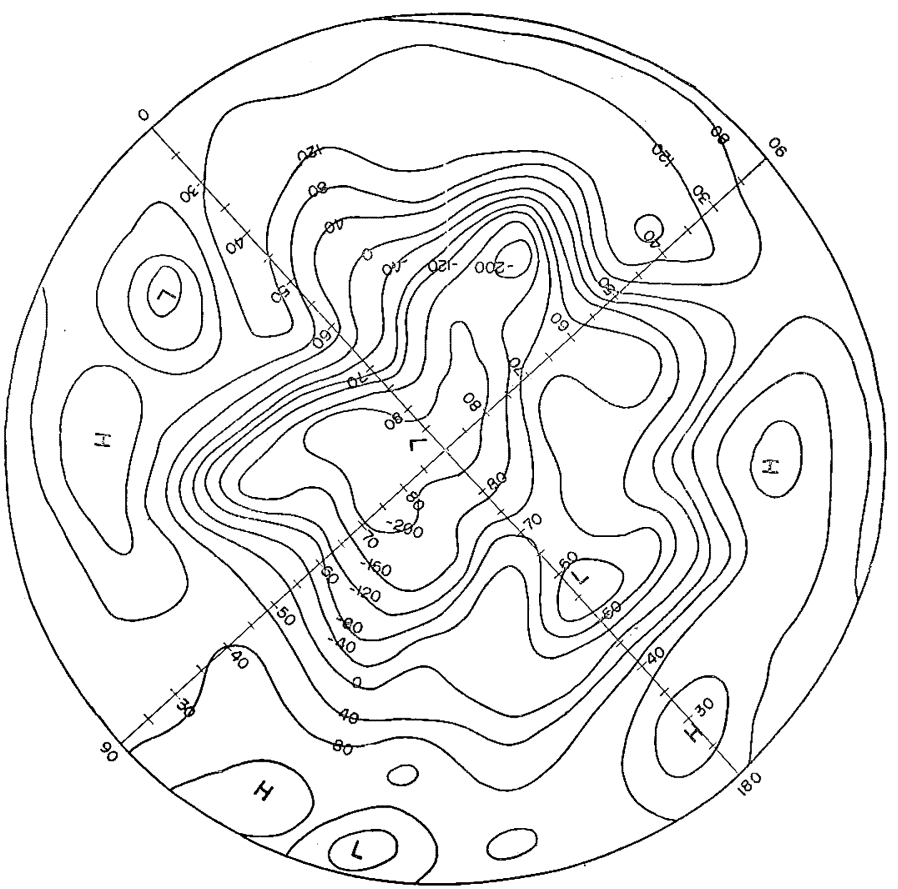

Fig. 2. Chart $(\psi)$ for 1958, Sept. 14, $500 \mathrm{mb}$. 


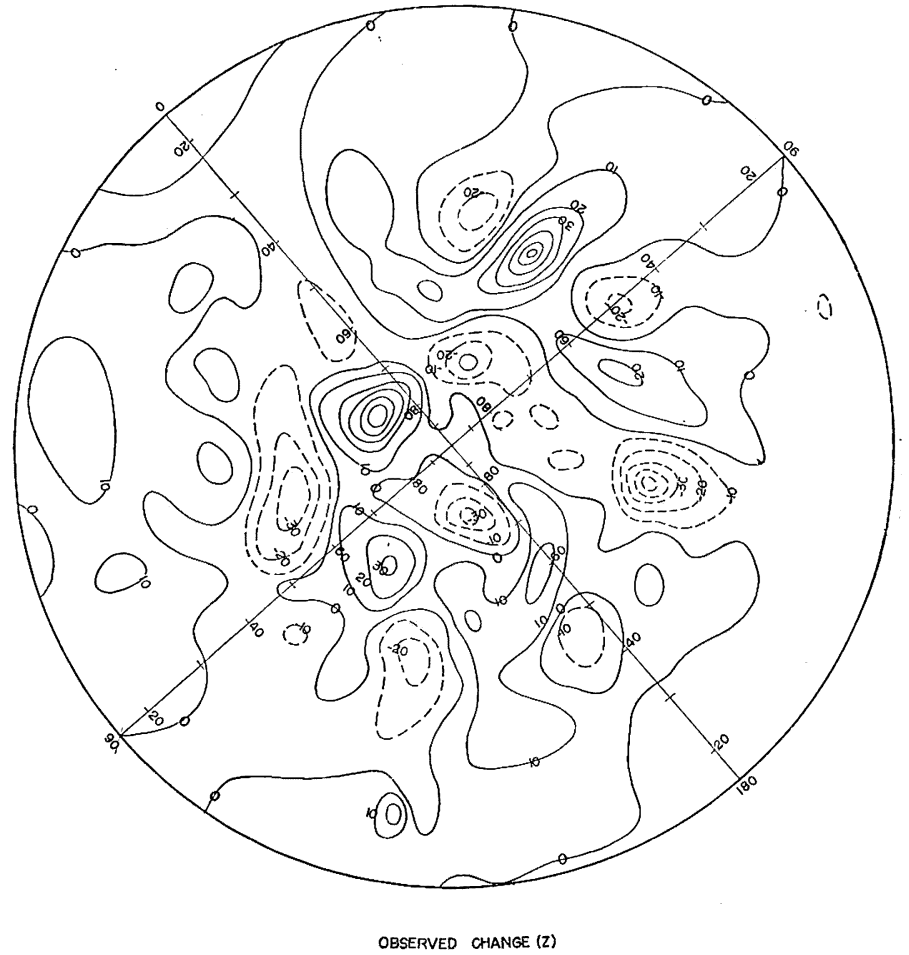

Fig. 3. 24-hour time change of $Z$-pattern for 1958 , Sept. $14 \sim 15$ th.

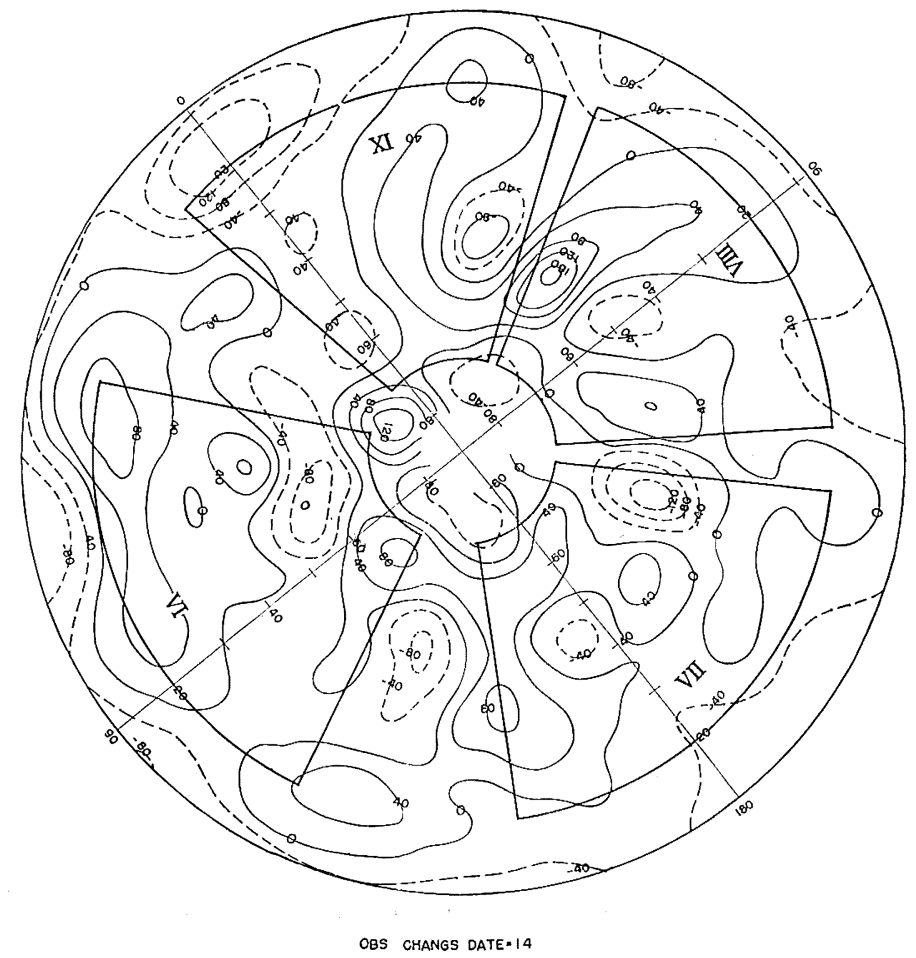

Fig. 4. The same (observed) for $\phi$-pattern with Fig. 3. 


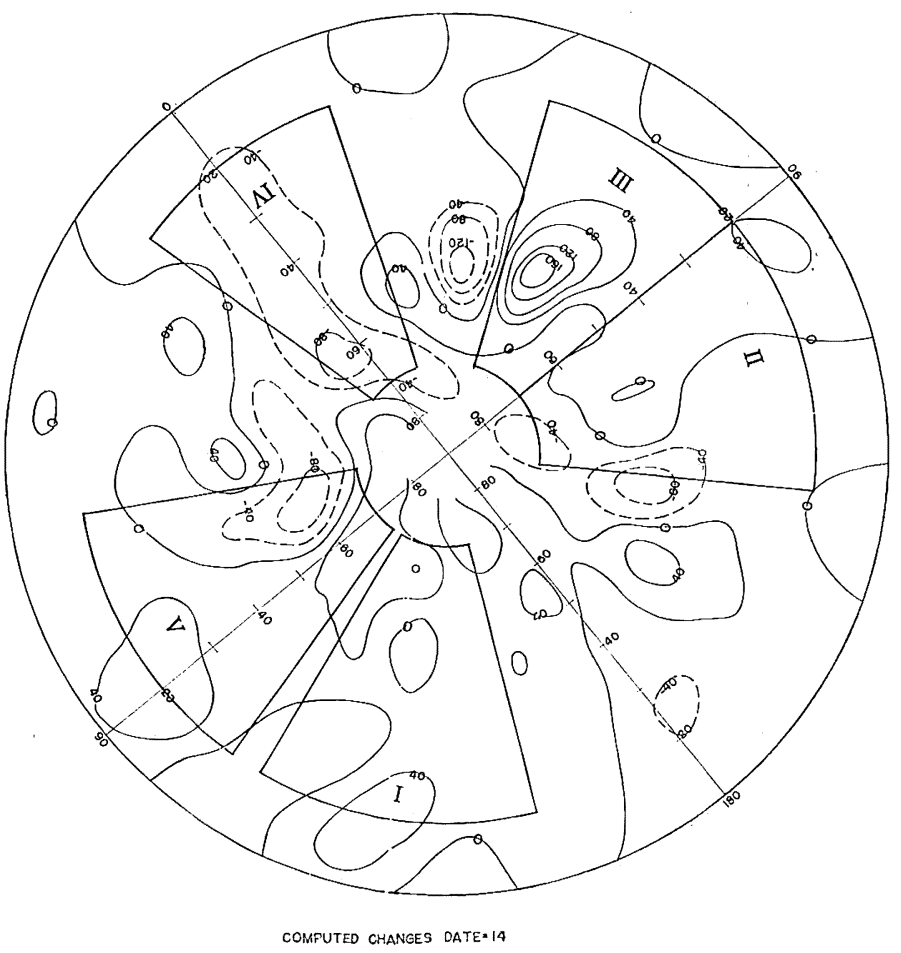

Fig. 5. Computed 24-hour time change of $\phi$-pattern.

Namely, we integrated the vorticity equation, assuming the barotropic atmosphere for $500-\mathrm{mb}$ level over the northern hemisphere.

At first, we investigated the degree of resemblance of the pattern expressed by $\phi$ (Fig. 1) used in our method to that by height $Z$ (Fig. 2). From a comparison of these two figures it may be found that the patterns of contours resemble each other very much, except for small discrepancies especially in the lower latitudes.

Next, we compared the observed time changes of these patterns (Figs. 3 and 4), and it was noticed that the general behaviour of those patterns is similar to each other, but the magnitude of changes, as can be imagined easily from the relation (18), is diminished for $\psi$-pattern in the higher latitudes and exaggerated in the lower latitudes as compared with $Z$-pattern.

Fig. 5 shows the computed time change of $\phi$-pattern in twenty-four hours, and we calculated the correlation coefficients between the observed and the computed 24-hour time changes of stream function $\phi$ as tabulated in Table 7, by use of such grid points as shown in Fig. 6.

In this table the numerals indicating the longitude denote the initial longitudes of various areas in which the coefficients were calculated and those areas are indicated by the closed heavy fan-shaped lines* in Figs. 4 and 5 . In those calcula-

* These areas are incorrectly displaced towards east by five degree for the west longitude. 
Table 7.

\begin{tabular}{|c|c|c|c|}
\hline $\begin{array}{l}\text { INIT. } \\
\text { LONG. }\end{array}$ & CORR. COEF. & $\begin{array}{l}\text { STAND. DEV. } \\
\text { OBS. VALUES }\end{array}$ & $\begin{array}{l}\text { STAND. DEV. } \\
\text { COMP. VALUES }\end{array}$ \\
\hline I $110 \mathrm{E}$ & $31 \quad(0.555)$ & 33.435 (45.955) & $24.336 \quad 23$ \\
\hline II $140 \mathrm{~W}$ & $0.677 \quad(0.723)$ & $38.453 \quad(44.641)$ & $37.805(31.436)$ \\
\hline III $95 \mathrm{~W}$ & $0.671(0.880)$ & $45.921 \quad(57.344)$ & $35.364 \quad(49.037)$ \\
\hline IV $25 \mathrm{~W}$ & $85(0$. & $45.660(34.563)$ & $380 \quad(33$. \\
\hline $\mathrm{V} \quad 60 \mathrm{E}$ & $25(0$. & $37.762(41.547)$ & $40 \quad(42$ \\
\hline $\mathrm{VI} \quad 40 \mathrm{E}$ & $5(0$ & 43.799 (4.3. & $83(40$ \\
\hline VII $150 \mathrm{E}$ & $0.476<0.6$ & $37.015(48.282)$ & $23.117 \quad(31.605)$ \\
\hline VIII $130 \mathrm{~W}$ & $0.617 \quad(0.741)$ & $40.170(44.747)$ & $36.658(43.622)$ \\
\hline IX $60 \mathrm{~W}$ & $0.724(0.757)$ & $48.923(44.584)$ & $37.261 \quad(44.463)$ \\
\hline
\end{tabular}

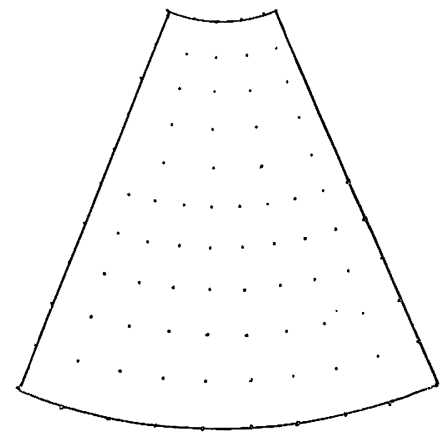

Fig. 6. Grid points used in calculations of correlation coefficients.

tions of correlation coefficients the values north of $20^{\circ}$ degree latitude circle are contained, and the values of correlation coefficients can be improved when we use the data north of $30^{\circ}$ latitude circle, because our data cover only the area north of $15^{\circ}$ latitude circle, as shown by the numerals in parentheses in Table 7.

These values inform us that 1) as is generally expected from the nature of surface spherical harmonic functions, the results are worse in the higher and the lower latitudes because the magnitudes of computed values were far smaller than the observed ones in those areas and relatively good in the middle latitudes, 2) the result near Japan is worst because this calculation could not indicate the deepening of the low north of Japan and the southward displacement of the developing anticyclone east of Japan. These, together with the existence of the typhoon south of Formosa, could not explain the actual change in the behaviour of the atmosphere.

Next, let us see the spectral distributions of observed and computed changes in the stream function $\phi$, which are shown in Table 8.

Table 8.

(a) Spectral distribution of the observed changes.

\begin{tabular}{|c|c|c|c|c|c|c|c|c|c|}
\hline$M^{\Lambda}$ & $\bar{N}-\bar{M}$ & 1 & 3 & 5 & 7 & 9 & 11 & 13 & 15 \\
\hline 0 & $\begin{array}{l}\mathrm{A} \\
\mathrm{B}\end{array}$ & $\begin{array}{l}0 \\
0\end{array}$ & $\begin{array}{l}7.87 \\
-0\end{array}$ & -11.88 & $\begin{array}{l}15.79 \\
-0\end{array}$ & $\begin{array}{c}-20.49 \\
0\end{array}$ & $\begin{array}{l}11.23 \\
-0\end{array}$ & $\begin{array}{c}-4.67 \\
0\end{array}$ & $-0^{8.53}$ \\
\hline 1 & $\begin{array}{l}\mathrm{A} \\
\mathrm{B}\end{array}$ & $\begin{array}{l}1.28 \\
1.96\end{array}$ & $\begin{array}{r}0.53 \\
-6.40\end{array}$ & $\begin{array}{r}-0.63 \\
10.73\end{array}$ & $\begin{array}{l}10.68 \\
14.14\end{array}$ & $\begin{array}{r}5.97 \\
-2.47\end{array}$ & $\begin{array}{l}6.15 \\
1.65\end{array}$ & $\begin{array}{r}-0.30 \\
-13.93\end{array}$ & $\begin{array}{l}-8.86 \\
-0.14\end{array}$ \\
\hline 2 & $\begin{array}{l}\mathrm{A} \\
\mathrm{B}\end{array}$ & $\begin{array}{l}-5.83 \\
-5.04\end{array}$ & $\begin{array}{r}7.25 \\
-12.09\end{array}$ & $\begin{array}{l}-1.86 \\
-3.97\end{array}$ & $\begin{array}{r}2.84 \\
10.06\end{array}$ & $\begin{array}{l}10.36 \\
16.12\end{array}$ & $\begin{array}{r}-7.28 \\
13.09\end{array}$ & $\begin{array}{l}8.52 \\
3.66\end{array}$ & $\begin{array}{r}0.37 \\
-4.78\end{array}$ \\
\hline 3 & $\begin{array}{l}\mathrm{A} \\
\mathrm{B}\end{array}$ & $\begin{array}{r}-12.89 \\
9.53\end{array}$ & $\begin{array}{r}-0.71 \\
3.61\end{array}$ & $\begin{array}{r}4.59 \\
-0.09\end{array}$ & $\begin{array}{r}-1.03 \\
2.09\end{array}$ & $\begin{array}{r}7.74 \\
-1.40\end{array}$ & $\begin{array}{r}-3.69 \\
1.54\end{array}$ & $\begin{array}{l}0.56 \\
0.62\end{array}$ & $\begin{array}{r}-0.57 \\
7.80\end{array}$ \\
\hline 4 & $\begin{array}{l}\mathrm{A} \\
\mathrm{B}\end{array}$ & $\begin{array}{r}-13.31 \\
-2.76\end{array}$ & $\begin{array}{r}10.28 \\
-5.35\end{array}$ & $\begin{array}{l}3.21 \\
3.89\end{array}$ & $\begin{array}{r}-4.29 \\
5.13\end{array}$ & $\begin{array}{l}6.84 \\
3.51\end{array}$ & $\begin{array}{r}-5.73 \\
6.03\end{array}$ & $\begin{array}{l}3.96 \\
2.58\end{array}$ & $\begin{array}{r}-2.92 \\
2.67\end{array}$ \\
\hline 5 & $\begin{array}{l}\mathrm{A} \\
\mathrm{B}\end{array}$ & $\begin{array}{l}-6.44 \\
-2.28\end{array}$ & $\begin{array}{l}4.50 \\
1.61\end{array}$ & $\begin{array}{r}-10.62 \\
3.68\end{array}$ & $\begin{array}{r}-12.70 \\
-0.67\end{array}$ & $\begin{array}{r}-2.28 \\
2.68\end{array}$ & $\begin{array}{l}-5.59 \\
-3.01\end{array}$ & $\begin{array}{r}4.26 \\
-7.55\end{array}$ & $\begin{array}{r}-2.17 \\
2.04\end{array}$ \\
\hline 6 & $\begin{array}{l}\mathrm{A} \\
\mathrm{B}\end{array}$ & $\begin{array}{r}-15.35 \\
-4.63\end{array}$ & $\begin{array}{r}7.44 \\
-3.85\end{array}$ & $\begin{array}{r}8.39 \\
-2.86\end{array}$ & $\begin{array}{l}-0.95 \\
-0.50\end{array}$ & $\begin{array}{r}-3.37 \\
2.67\end{array}$ & $\begin{array}{r}-9.70 \\
0.71\end{array}$ & $\begin{array}{l}4.50 \\
1.38\end{array}$ & $\begin{array}{r}-1.87 \\
1.29\end{array}$ \\
\hline
\end{tabular}


1961 Barotropic Forecasting with the Use of Surface Spherical Harmonic Representations

\begin{tabular}{rl|rrrrrrrr}
7 & $\mathrm{~A}$ & -8.92 & 3.64 & 5.03 & 2.43 & 3.23 & -4.41 & -0.97 & -1.26 \\
& $\mathrm{~B}$ & 2.65 & -13.49 & -15.96 & -7.56 & 0.42 & 4.96 & -1.62 & -1.05 \\
8 & $\mathrm{~A}$ & -1.13 & -17.99 & -16.16 & -6.23 & -0.97 & 4.82 & 1.90 & -0.05 \\
& $\mathrm{~B}$ & -0.10 & 13.37 & 8.22 & 1.36 & 0.61 & -3.22 & 0.97 & 0.60 \\
9 & $\mathrm{~A}$ & 7.20 & -2.01 & -3.79 & -1.41 & -2.95 & -1.41 & 0.30 & 3.36 \\
& $\mathrm{~B}$ & 0.84 & 2.36 & 2.68 & 1.06 & 0.18 & -1.00 & -1.72 & -0.64 \\
10 & $\mathrm{~A}$ & -1.98 & -1.83 & 0.57 & -4.20 & -3.35 & 3.25 & 0.75 & -0.67 \\
& $\mathrm{~B}$ & 6.07 & 5.34 & 8.13 & 5.01 & -1.15 & -1.17 & -1.36 & 1.30 \\
11 & $\mathrm{~A}$ & -3.07 & -1.47 & -3.11 & 0.54 & 2.75 & -1.85 & -1.20 & -0.21 \\
& $\mathrm{~B}$ & -2.47 & -0.11 & 1.52 & 1.13 & 0.77 & 1.29 & 0.86 & -0.42 \\
12 & $\mathrm{~A}$ & -6.06 & 1.57 & 0.26 & 2.28 & 5.01 & -0.54 & -0.43 & 0.34 \\
& $\mathrm{~B}$ & -3.54 & -0.51 & -4.01 & -5.54 & -2.23 & -1.84 & -0.47 & 0.27 \\
\hline
\end{tabular}

(b) Spectral distributions of the computed changes.

\begin{tabular}{|c|c|c|c|c|c|c|c|c|}
\hline$N-M$ & 1 & 3 & 5 & 7 & 9 & 11 & 13 & 15 \\
\hline 0 & $\begin{array}{r}-0.00 \\
0.00\end{array}$ & $\begin{array}{r}-2.11 \\
0.00\end{array}$ & $\begin{array}{r}2.99 \\
-0.00\end{array}$ & $\begin{array}{r}2.49 \\
-0.00\end{array}$ & $\begin{array}{r}1.09 \\
-0.00\end{array}$ & $\begin{array}{l}0.36 \\
0.00\end{array}$ & $\begin{array}{r}-0.57 \\
0.00\end{array}$ & $\begin{array}{l}1.85 \\
0.01\end{array}$ \\
\hline 1 & $\begin{array}{r}-12.29 \\
5.89\end{array}$ & $\begin{array}{r}-8.43 \\
1.18\end{array}$ & $\begin{array}{r}0.95 \\
12.36\end{array}$ & $\begin{array}{l}4.70 \\
8.26\end{array}$ & $\begin{array}{l}6.12 \\
3.22\end{array}$ & $\begin{array}{l}1.43 \\
1.54\end{array}$ & $\begin{array}{r}0.23 \\
-1.98\end{array}$ & $\begin{array}{l}-3.51 \\
-2.56\end{array}$ \\
\hline 2 & $\begin{array}{l}-20.65 \\
-10.44\end{array}$ & $\begin{array}{r}0.71 \\
-13.10\end{array}$ & $\begin{array}{l}-2.27 \\
-4.50\end{array}$ & $\begin{array}{l}0.56 \\
3.15\end{array}$ & $\begin{array}{r}0.73 \\
11.11\end{array}$ & $\begin{array}{r}-2.19 \\
3.70\end{array}$ & $\begin{array}{l}4.87 \\
4.30\end{array}$ & $\begin{array}{r}2.84 \\
-0.55\end{array}$ \\
\hline 3 & $\begin{array}{r}-9.87 \\
10.14\end{array}$ & $\begin{array}{r}-3.46 \\
2.01\end{array}$ & $\begin{array}{r}3.69 \\
-4.42\end{array}$ & $\begin{array}{r}0.68 \\
-1.45\end{array}$ & $\begin{array}{l}-3.48 \\
-0.01\end{array}$ & $\begin{array}{r}-3.82 \\
1.83\end{array}$ & $\begin{array}{r}-2.18 \\
1.43\end{array}$ & $\begin{array}{r}1.01 \\
-0.69\end{array}$ \\
\hline 4 & $\begin{array}{l}0.83 \\
5.61\end{array}$ & $\begin{array}{r}7.37 \\
10.45\end{array}$ & $\begin{array}{r}2.44 \\
-0.88\end{array}$ & $\begin{array}{l}0.07 \\
2.52\end{array}$ & $\begin{array}{r}-2.37 \\
7.14\end{array}$ & $\begin{array}{r}-1.04 \\
4.83\end{array}$ & $\begin{array}{l}2.62 \\
2.24\end{array}$ & $\begin{array}{l}2.58 \\
0.07\end{array}$ \\
\hline 5 & $\begin{array}{l}1.87 \\
0.37\end{array}$ & $\begin{array}{l}-2.26 \\
-2.58\end{array}$ & $\begin{array}{l}-6.23 \\
-2.93\end{array}$ & $\begin{array}{r}-5.29 \\
2.78\end{array}$ & $\begin{array}{r}-5.56 \\
2.61\end{array}$ & $\begin{array}{l}+2.19 \\
-2.58\end{array}$ & $\begin{array}{r}3.18 \\
-0.99\end{array}$ & $\begin{array}{l}1.82 \\
1.19\end{array}$ \\
\hline 6 & $\begin{array}{r}-12.57 \\
0.67\end{array}$ & $\begin{array}{r}-0.56 \\
-10.07\end{array}$ & $\begin{array}{r}5.48 \\
-7.79\end{array}$ & $\begin{array}{l}-0.27 \\
-1.47\end{array}$ & $\begin{array}{r}-5.02 \\
2.60\end{array}$ & $\begin{array}{r}-3.80 \\
3.00\end{array}$ & $\begin{array}{l}0.41 \\
2.69\end{array}$ & $\begin{array}{l}1.97 \\
2.30\end{array}$ \\
\hline 7 & $\begin{array}{l}-3.22 \\
-4.13\end{array}$ & $\begin{array}{r}0.37 \\
-11.32\end{array}$ & $\begin{array}{r}2.67 \\
-10.10\end{array}$ & $\begin{array}{r}0.20 \\
-6.01\end{array}$ & $\begin{array}{l}-2.50 \\
-0.58\end{array}$ & $\begin{array}{r}-1.97 \\
2.08\end{array}$ & $\begin{array}{l}-0.57 \\
-0.25\end{array}$ & $\begin{array}{l}-0.14 \\
-0.80\end{array}$ \\
\hline 8 & $\begin{array}{l}-1.09 \\
-7.09\end{array}$ & $\begin{array}{r}-9.40 \\
0.82\end{array}$ & $\begin{array}{r}-11.32 \\
0.68\end{array}$ & $\begin{array}{r}-5.03 \\
0.13\end{array}$ & $\begin{array}{r}-0.80 \\
0.21\end{array}$ & $\begin{array}{r}3.45 \\
-1.91\end{array}$ & $\begin{array}{l}3.30 \\
0.07\end{array}$ & $\begin{array}{r}0.62 \\
-1.15\end{array}$ \\
\hline 9 & $\begin{array}{r}-1.73 \\
5.51\end{array}$ & $\begin{array}{r}-1.56 \\
4.97\end{array}$ & $\begin{array}{r}-3.09 \\
7.34\end{array}$ & $\begin{array}{r}-4.31 \\
5.54\end{array}$ & $\begin{array}{l}-4.75 \\
-0.08\end{array}$ & $\begin{array}{l}-1.27 \\
-1.56\end{array}$ & $\begin{array}{l}2.46 \\
0.09\end{array}$ & $\begin{array}{l}2.64 \\
1.41\end{array}$ \\
\hline 10 & $\begin{array}{r}-6.04 \\
0.56\end{array}$ & $\begin{array}{l}-0.51 \\
-3.58\end{array}$ & $\begin{array}{r}-0.66 \\
4.89\end{array}$ & $\begin{array}{r}-4.92 \\
4.88\end{array}$ & $\begin{array}{r}-2.44 \\
0.29\end{array}$ & $\begin{array}{l}0.26 \\
0.11\end{array}$ & $\begin{array}{r}0.79 \\
-2.72\end{array}$ & $\begin{array}{l}-0.11 \\
-0.25\end{array}$ \\
\hline 11 & $\begin{array}{r}5.02 \\
-4.03\end{array}$ & $\begin{array}{r}-0.38 \\
4.32\end{array}$ & $\begin{array}{l}0.70 \\
2.51\end{array}$ & $\begin{array}{l}3.35 \\
2.67\end{array}$ & $\begin{array}{l}1.72 \\
2.99\end{array}$ & $\begin{array}{r}1.66 \\
-1.99\end{array}$ & $\begin{array}{r}1.05 \\
-1.50\end{array}$ & $\begin{array}{l}-0.24 \\
-1.79\end{array}$ \\
\hline 12 & $\begin{array}{l}0.71 \\
1.33\end{array}$ & $\begin{array}{l}-2.51 \\
-4.68\end{array}$ & $\begin{array}{r}3.38 \\
-7.18\end{array}$ & $\begin{array}{r}6.14 \\
-6.14\end{array}$ & $\begin{array}{r}2.89 \\
-3.89\end{array}$ & $\begin{array}{r}2.97 \\
-1.13\end{array}$ & $\begin{array}{l}0.94 \\
1.55\end{array}$ & $\begin{array}{l}0.06 \\
0.44\end{array}$ \\
\hline
\end{tabular}

Then it will be noticed that the change in the zonal component can not be computed by this procedure, but the general behaviour of changes in other components of smaller wave numbers can be explained.

We suppose that the fact that the behaviour of the zonal flow can not be computed may be attributed to the variable Coriolis parameter in the conversion of height $Z$ into the stream function $\phi$. Namely, the error of observations near the equator exerts a great influence over our estimation of the behaviour of the zonal current. On the contrary, the magnitude of computed changes in the stream functions $\phi$ is found to be very little in the lower latitudes. Why? 
In these calculations, changes in total kinetic energies expressed by the following relation :

$$
\ddot{k}=\sum_{n=|m|+1}^{n^{\prime}} \sum_{m=-m^{\prime}}^{m^{\prime}} n(n+1)\left|\Psi_{n}^{m}\right|^{2},
$$

could be observed only to a slight degree, amounting only to $0.18 \%$ for one day, as shown in Fig. 7.

This suggests that this scheme will prove fruitful for long-range weather forecasting, because it is supposed to be advantageous in avoiding the spatial truncation errors and further troubles accompanying the boundary conditions in the usual grid method. Further, the

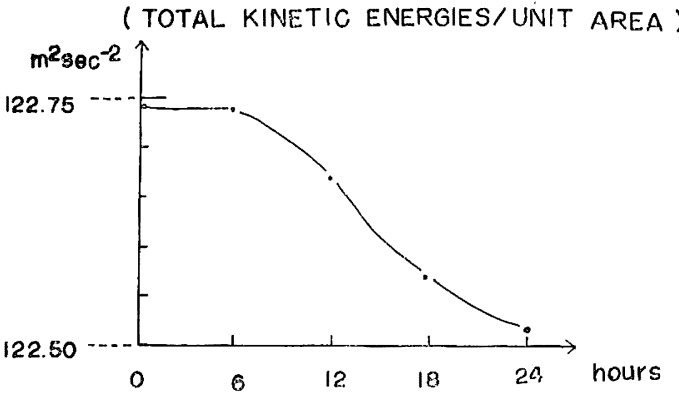

Fig. 7. Time change in total kinetic energies. total kinetic energies were remarkably increased during this period up to $179.66 \mathrm{~m}^{2}$ $\mathrm{sec}^{-1} / \mathrm{cm}$.

\section{Appendix}

Computation of the Associated Normalized Function

$$
P_{n}^{m}(x)=\sqrt{\frac{2 n+1}{2} \frac{(n+m) !}{4^{m}(m !)^{2}(n-m) !}}\left(1-x^{2}\right)^{\frac{m}{2}} F(\alpha, \beta, \gamma ; z),
$$

here,

$$
\begin{aligned}
& F(\alpha, \beta, \gamma ; z)=1+\sum \frac{\alpha(\alpha+1) \cdots \cdots(\alpha+K-1) \beta(\beta+1) \cdots \cdots(\beta+K-1)}{K ! \gamma(\gamma+1) \cdots \cdots(\gamma+K-1)} z^{K}, \\
& \alpha=-(n-m), \\
& \beta=n+m+1, \\
& \gamma=m+1, \\
& z=(1-x) / z \\
& x=\sin x .
\end{aligned}
$$

The direct computation using the above expansion formula was found to be accompanied with much trouble because the factorial terms are very large in higher orders of $P_{n}^{m}$, which must minimize the precision of the calculated value.

The following is the computation program we used:

i) $P_{n}^{n}$ for $m=n$ was calculated from

$$
P_{m}^{m}=\sqrt{\frac{2 m+1}{2 m}} \cos x P_{m-1}^{m-1},
$$

with

$$
\begin{aligned}
& P_{0}^{0}=\sqrt{1 / 2} \\
& P_{1}^{1}=\sqrt{3 / 4} \cos x
\end{aligned}
$$


ii) And the recurrence formula,

$$
P_{m+1}^{m}=\sqrt{2 m+3} \sin x P_{m}^{m} .
$$

was used for calculation of $P_{n}^{m}$.

iii) Namely, with $P_{n}^{m}$ and $P_{m+1}^{m}$ that we have got so far, we can compute all values successively from the recurrence formula,

$$
P_{n}^{m}=\sqrt{\frac{(2 n+1)(2 n-1)}{(n+m)(n-m)}} \sin x P_{n-1}^{m}-\sqrt{\frac{(2 n+1)(n+m-1)(n-m-1)}{(2 n-3)(n+m)(n-m)}} P_{n-2}^{m} .
$$

Further, we didn't use the double precision method in our computation, but the values could be considered reliable as far as the digit of $10^{-6}$ at least.

Acknowledgement_- The authors wish to express their thanks to Dr. H. Arakawa and Prof. S. Syono, who gave them encouragements throughout this work, and to Dr. H. Itoo, who cordially gave them the permission to use the IBM 704 . They also wish to thank Prof. K. MiYakoda for his encouraging and stimulating discussions. Finally, the authors wish to thank Miss AkiYAMA, who performed the laborious task of computations for them.

\section{References}

Silberman, I., 1954: Planetary waves in the atmosphere. Jour. Met., 11, 27-34.

HAURWITZ, B., 1940: The motion of atmospheric disturbance on a spherical earth. Journ. Mar. Research, 3, 254-267.

INFELd, L., and T. E. HuLL, 1951: The factorization method. Rev. Mod. Phys., 23, 21-68.

\section{球函数表示を用いた順正予報}

䆶田正八・広瀬元孝・菊池幸雄・列原宜夫

球函数表示を用いると，格子点による方法江伴うよろな空間愦差は存在しないので，将来，長期予報飞 役立つと思う。もらろん，それはとれなりに厄介な問題もあるが，ここでは一応，北半球順圧予報方式の 技術的説朋，誤差分布妿らみて妥当と思われる波数の決定，2つの波が干涉して 1 つの波を作るとき用い

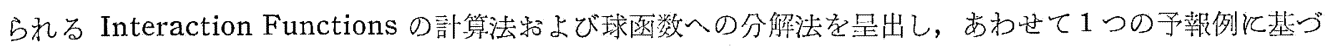
き, $f \nabla^{2} \psi=\nabla^{2} Z$ の変換の問題などを見た。

な特，相関係数は 0.73 程度，全運動エネルギーの時間变動は $0.18 \%$ 飞過ぎなかつた。 